\title{
Design and Synthesis of Cu@CuS Yolk-Shell Structures with Enhanced Photocatalytic Activity
}

\author{
Qiuyan $\mathrm{Li}^{1} \cdot$ Fan Wang ${ }^{1} \cdot$ Linqiang $\mathrm{Sun}^{1} \cdot$ Zhe Jiang $^{1}$ • \\ Tingting Ye ${ }^{1} \cdot$ Meng Chen $^{1} \cdot$ Qiang Bai $^{2} \cdot$ Chao Wang ${ }^{1}$. \\ Xiguang Han $^{1}$
}

Received: 14 December 2016/ Accepted: 26 January 2017/Published online: 1 March 2017

(c) The Author(s) 2017. This article is published with open access at Springerlink.com

\section{Highlights}

- Non-spherical Cu@CuS yolk-shell structures with different morphologies, including octahedral, truncated octahedral, and cuboctahedral shapes, are successfully obtained using a strategy combining shell sulfidation and core disproportionation reaction.

- The as-prepared $\mathrm{Cu} @ \mathrm{CuS}$ structures exhibited clearly remarkable photocatalytic performance.

\begin{abstract}
Non-spherical $\mathrm{Cu} @ \mathrm{CuS}$ yolk-shell structures are successfully obtained using $\mathrm{Cu}_{2} \mathrm{O}$ cube templates in a process combining rapid surface sulfidation followed by disproportionation of the $\mathrm{Cu}_{2} \mathrm{O}$ core upon treatment with a hydrochloric acid solution. By employing the above method, $\mathrm{Cu} @ \mathrm{CuS}$ yolk-shell structures with different morphologies, including octahedral, truncated octahedral, and cuboctahedral shapes, can be synthesized. The void space within the hollow structures provides a unique confined space, where the metallic copper present in the core of a shell can be protected from agglomeration and oxidation. Furthermore, the presence of metal copper in these hollow structures
\end{abstract}

Qiuyan Li and Fan Wang have contributed equally to this work.

Electronic supplementary material The online version of this article (doi:10.1007/s40820-017-0135-7) contains supplementary material, which is available to authorized users.

Xiguang Han

xghan@jsnu.edu.cn

1 Jiangsu Key Laboratory of Green Synthetic Chemistry for Functional Materials, Department of Chemistry, School of Chemistry and Chemical Engineering, Jiangsu Normal University, Xuzhou 221116, People's Republic of China

2 College of Materials Science and Engineering, Qingdao University of Science and Technology, Qingdao 266042, People's Republic of China contributes to improvement in the photocatalytic properties of these materials. The application of these $\mathrm{Cu} @ \mathrm{CuS}$ structures indeed shows clearly improved photocatalytic performance.

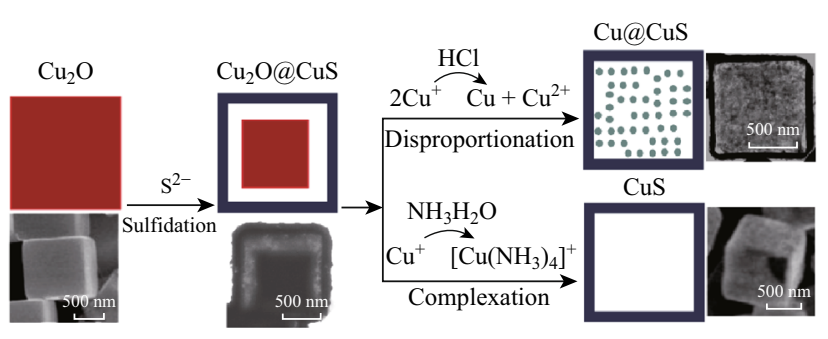

Keywords Nanomaterial · Yolk-shell structure · $\mathrm{Cu} @ \mathrm{CuS} \cdot$ Photocatalysis

\section{Introduction}

Photocatalytic technology can be used to convert solar energy into chemical energy and constitutes a promising approach to combat both environmental pollution and the global energy shortage [1-4]. Metal sulfides have been drawing attention as new photocatalytic materials owing to 
their narrow band gap, good light adsorption properties, and excellent photocatalytic performance [5, 6]. In particular, copper sulfides $\left(\mathrm{Cu}_{x} \mathrm{~S}\right.$ with $\left.x=1-2\right)$ are transition metal chalcogenides that have been found to be potentially useful materials for application in photocatalysis due to their low cost, high stability, and low cytotoxicity [7]. Recently, many varieties of copper sulfides micro-/nanostructures have been synthesized to improve their photocatalytic efficiency, including nanotubes [8], nanowires [9], nanorods [10], nanoplates [11], ball-flower [12], and hollow cages [13]. However, the photocatalytic activity of pure copper sulfides under visible light irradiation is not high enough for practical applications due to drawbacks associated with their narrow band gap, which results in the easy recombination of the photogenerated charges.

To address this issue, various methods have been developed, such as a controllable synthesis by doping with different ions [14, 15], sensitization by absorbed molecules or quantum dots [16, 17], and coupling with different bandgap semiconductors [18]. Among these, the modification of a photocatalyst with noble metals such as $\mathrm{Pt}, \mathrm{Au}$, and $\mathrm{Ag}$ is a meaningful and efficient strategy, since these metals can act as electron sinks to effectively transfer the photogenerated electrons, thus improving the corresponding photocatalytic performance [19-21]. Compared to noble metals, copper is particularly interesting due to its high conductivity combined with a much lower cost. However, deposition of copper on a photocatalyst surface is not always useful in photocatalysis since copper particles have a strong tendency to agglomerate and can be easily oxidized during the preparation and utilization processes [22].

Compared to other dense structures of the same size, yolk-shell nanostructures with a void space between the interior core and the mesoporous outer shell have attracted a great deal of attention due to their special structure and properties, such as low density, large surface area, and high loading capacity [23-28]. The void space within the yolk-shell structures provides a unique confined space, where a metal present as the yolk in the core of a shell can be protected from agglomeration and oxidation [29]. In general, various yolk-shell nanoparticles (NPs) have been synthesized by selectively scarifying the core/shell layer or converting the core materials via a disproportionation reaction [30], galvanic reaction [31, 32], or the Kirkendall effect [33]. However, most of the studies on the preparation of yolk-shell NPs focus on a noble metal, such as $\mathrm{Au}, \mathrm{Ag}$, and $\mathrm{Pt}$, as the core and a metal oxide as the shell. Investigations on nanostructures using copper as the core and metal sulfides as the shell have been relatively limited. Therefore, it is still desirable to develop new efficient strategies to fabricate $\mathrm{Cu} @$ metal sulfides with high-performance photocatalytic activity.
Herein, we developed a strategy combining a shell sulfidation and core disproportionation reaction to synthesize uniform, non-spherical $\mathrm{Cu} @ \mathrm{CuS}$ yolk-shell structures. When evaluated as photocatalytic materials, the $\mathrm{Cu} @ \mathrm{CuS}$ structures showed a clear improvement in their photocatalytic performance.

\section{Experimental}

\subsection{Chemicals}

Copper(II) sulfate pentahydrate $\left(\mathrm{CuSO}_{4} \cdot 5 \mathrm{H}_{2} \mathrm{O}\right)$, cupric acetate monohydrate $\left[\mathrm{Cu}\left(\mathrm{CH}_{3} \mathrm{COO}\right)_{2} \cdot \mathrm{H}_{2} \mathrm{O}\right]$, trisodium citrate dihydrate $\left(\mathrm{Na}_{3} \mathrm{C}_{6} \mathrm{H}_{5} \mathrm{O}_{7} \cdot 2 \mathrm{H}_{2} \mathrm{O}\right)$, sodium hydroxide $(\mathrm{NaOH})$, ascorbic acid $\left(\mathrm{C}_{6} \mathrm{H}_{8} \mathrm{O}_{6}\right)$, sodium sulfide $\left(\mathrm{Na}_{2-}\right.$ $\left.\mathrm{S} \cdot 9 \mathrm{H}_{2} \mathrm{O}\right)$, hydrochloric acid $(\mathrm{HCl})$, ammonia $\left(\mathrm{NH}_{3} \cdot \mathrm{H}_{2} \mathrm{O}\right)$, and D-glucose $\left(\mathrm{C}_{6} \mathrm{H}_{12} \mathrm{O}_{6}\right)$ were all purchased from Sinopharm Chemical Reagent Co., Ltd.

\subsection{Synthesis of the Materials}

\subsubsection{Synthesis of $\mathrm{Cu}_{2} \mathrm{O}$ Solid Cubes}

In a typical synthesis, $\mathrm{CuSO}_{4} \cdot 5 \mathrm{H}_{2} \mathrm{O}(0.375 \mathrm{~g}, 1.5 \mathrm{mmol})$ was dissolved in $100 \mathrm{~mL}$ of distilled water under vigorous stirring treatment to form solution 1. Subsequently, $\mathrm{Na}_{3} \mathrm{C}_{6} \mathrm{H}_{5} \mathrm{O}_{7} \cdot 2 \mathrm{H}_{2} \mathrm{O} \quad(0.15 \mathrm{~g}, \quad 0.51 \mathrm{mmol})$ and $\mathrm{NaOH}(1 \mathrm{~g}, 25 \mathrm{mmol})$ were added to the above solution 1. Ascorbic acid $(0.264 \mathrm{~g} 1.5 \mathrm{mmol})$ was dissolved in $50 \mathrm{~mL}$ of distilled water under ultrasonic treatment to form solution 2. Solution 2 was mixed with solution 1 at room temperature $\left(25^{\circ} \mathrm{C}\right)$, and the resulting mixture was stirred for $40 \mathrm{~min}$ at room temperature. A red product was obtained by centrifugation and washed with deionized water and ethanol. The product was dried in oven at $60{ }^{\circ} \mathrm{C}$.

\subsubsection{Preparation of $\mathrm{Cu}_{2} \mathrm{O}$ Solid Octahedrons}

In a typical experiment, $\mathrm{Cu}\left(\mathrm{CH}_{3} \mathrm{COO}\right)_{2} \cdot \mathrm{H}_{2} \mathrm{O} \quad(3 \mathrm{~g}$, $15 \mathrm{mmol})$ was dissolved in deionized water $(20 \mathrm{~mL})$ under a constant stirring at $70{ }^{\circ} \mathrm{C}$ for $2 \mathrm{~min}$. When a sodium hydroxide solution $(10 \mathrm{~mL}, 9 \mathrm{M})$ was added to the above solution, a dark precipitate was produced. After stirring for $5 \mathrm{~min}$, D-glucose powder $(0.6 \mathrm{~g})$ was then added with constant stirring at $70{ }^{\circ} \mathrm{C}$ for $60 \mathrm{~min}$. A red product was obtained by centrifugation, washed with deionized water and ethanol, and then dried in oven at $60{ }^{\circ} \mathrm{C}$. The preparation of $\mathrm{Cu}_{2} \mathrm{O}$ solid truncated octahedrons is similar to that of $\mathrm{Cu}_{2} \mathrm{O}$ solid octahedrons, except for the concentration and volume of the $\mathrm{Cu}\left(\mathrm{CH}_{3} \mathrm{COO}\right)_{2} \cdot \mathrm{H}_{2} \mathrm{O}(50 \mathrm{~mL}, 0.3 \mathrm{M})$ and sodium hydroxide $(30 \mathrm{~mL}, 3 \mathrm{M})$ solutions. 
Cuboctahedral particles were also produced by a similar method, but the reaction time was reduced from 60 to 20 min.

\subsubsection{Preparation of $\mathrm{Cu}_{2} \mathrm{O} @ \mathrm{CuS}$ Yolk-Shell Structures}

In a typical synthesis, the $\mathrm{Cu}_{2} \mathrm{O}$ solid sample $(70 \mathrm{mg})$ was added into distilled water to form solution 3 , and then a sodium sulfide solution $(1 \mathrm{~mL}, 0.6 \mathrm{M})$ was added to the above solution, and stirred for $5 \mathrm{~min}$ at room temperature. The black products were collected by centrifugation, washed with distilled water, and then dried at $60{ }^{\circ} \mathrm{C}$ for further characterization.

\subsubsection{Preparation of $C u @ C u S$ Yolk-Shell Structures}

The above-synthesized black products $(70 \mathrm{mg})$ were dissolved in $10 \mathrm{~mL}$ of distilled water under ultrasonic treatment to form solution 4. Hydrochloric acid $(1 \mathrm{~mL})$ was then added to solution 4 at $80^{\circ} \mathrm{C}$. After stirring for $2 \mathrm{~h}$, the products were collected by centrifugation, washed, and dried at $60{ }^{\circ} \mathrm{C}$ for further characterization.

\subsubsection{Preparation of CuS Hollow Structures}

$\mathrm{CuS}$ particles were also prepared by a similar method together with $\mathrm{Cu} @ \mathrm{CuS}$ box structures, and ammonia was added to the black solution 4 instead of hydrochloric acid.

\subsection{Characterization}

The composition and phase of the as-prepared products were acquired by powder X-ray diffraction (XRD) using a Panalytical X-pert diffractometer with $\mathrm{CuK} \alpha$ radiation. The morphology and crystal structure of the as-prepared products were observed by scanning electron microscopy (SEM, SU8010) and high-resolution transmission electron microscopy (HRTEM, JEM-2100) with an acceleration voltage of $200 \mathrm{kV}$. All TEM samples were prepared by depositing a drop of the diluted suspensions in ethanol on a carbon-film-coated copper grid.

\subsection{Photocatalysis}

The photodegradation efficiency of methylene blue (MB) in aqueous solution was measured under sunlight irradiation (300 W xenon lamp). All experiments were carried out at the temperature of $25 \pm 2{ }^{\circ} \mathrm{C}$. Typically, $15 \mathrm{mg}$ of $\mathrm{Cu} @ \mathrm{CuS}$ yolk-shell sample was dispersed in $50 \mathrm{~mL}$ of $\mathrm{MB}$ aqueous solution $(0.02 \mathrm{M})$ under ultrasonic irradiation to form a suspension, which was magnetically stirred for $30 \mathrm{~min}$ in the dark. At regular irradiation time intervals, the dispersion was sampled and centrifuged to separate the residue. The photodegradation efficiency was monitored by measuring the absorbance of the centrifuged solutions at the maximum absorption wavelength of $664 \mathrm{~nm}$ using UV-Vis spectroscopy (SHIMADZU, UV-2100) at room temperature.

\section{Results and Discussion}

Our strategy for the formation of $\mathrm{Cu} @ \mathrm{CuS}$ yolk-shell structures is shown in Fig. 1a. In the first step, the $\mathrm{Cu}_{2} \mathrm{O}$ cubes used as precursors were prepared by a facile solvothermal method. The XRD pattern (Fig. S1) of the obtained products corresponds to the cubic $\mathrm{Cu}_{2} \mathrm{O}$ phase (JCPDS card no. 00-034-1354, $\alpha=0.4217 \mathrm{~nm}$ ), indicating that $\mathrm{Cu}_{2} \mathrm{O}$ was successfully synthesized. As shown in Fig. $1 \mathrm{~b}$, the synthesized uniform $\mathrm{Cu}_{2} \mathrm{O}$ cubes exhibit a smooth surface and have a mean size of about $1 \mu \mathrm{m}$. The $\mathrm{Cu}_{2} \mathrm{O}$ cubes can be easily converted into $\mathrm{Cu}_{2} \mathrm{O} @ \mathrm{CuS}$ yolkshell structures by a simple surface sulfidation process using $\mathrm{Na}_{2} \mathrm{~S}$ as sulfur source. XRD analysis was used to elucidate the composition and crystal phase of the as-prepared products. As shown in Fig. 2a, most of the diffraction peaks can be ascribed to hexagonal CuS (JCPDS card no. 01-078-0876), while a part of the peaks (marked with a star) corresponds to the primitive cubic $\mathrm{Cu}_{2} \mathrm{O}$ (JCPDS card no. 00-034-1354). Therefore, the as-prepared products are composite of $\mathrm{CuS}$ and $\mathrm{Cu}_{2} \mathrm{O}$ phases, and the reaction equation can be described as: $2 \mathrm{Cu}_{2} \mathrm{O}+4 \mathrm{~S}^{2-}+\mathrm{O}_{2}+4-$ $\mathrm{H}_{2} \mathrm{O} \rightarrow 4 \mathrm{CuS}+8 \mathrm{OH}^{-}$[34]. The morphologies of the products were analyzed by FESEM and TEM. As shown in Fig. 1c, the morphologies of the products still retain uniform cubes after the sulfidation process. The TEM images (inset of Fig. 1c) confirm the formation of yolk-shell structures by the obvious contrast between the cavity and the shell, which has a thickness of approximately $50 \mathrm{~nm}$. The formation process of the yolk-shell structures can be divided into a sulfidation step and the Kirkendall effect. Firstly, the sulfide ions released from $\mathrm{Na}_{2} \mathrm{~S}$ in the aqueous solution react with the metal ions on the surface of the $\mathrm{Cu}_{2} \mathrm{O}$ cubes to form a thin layer of $\mathrm{Cu}$ sulfides, and then the outward diffused metal ions become dominant compared to the inward diffusion of $\mathrm{S}^{2-}$ based on the Kirkendall effect, leading to the formation of a well-defined gap between the shell and the $\mathrm{Cu}_{2} \mathrm{O}$ core. Cuprous compounds can go through a disproportionation reaction to form $\mathrm{Cu}$ metal and $\mathrm{Cu}^{2+}$ ions under acidic conditions. Therefore, the cubic $\mathrm{Cu}_{2} \mathrm{O}$ core encapsulated in this system can be used to synthesize spatially confined $\mathrm{Cu}$ particles by a disproportionation reaction. When the $\mathrm{Cu}_{2} \mathrm{O} @ \mathrm{CuS}$ particles were added to a hydrochloric acid solution, the color of the solution turned blue-green (Fig. S2), indicating that the $\mathrm{Cu}^{2+}$ ions generated from the disproportionation reaction can diffuse to the solution through the CuS shell. The SEM and TEM images (Fig. 1d) reveal that the $\mathrm{Cu}_{2} \mathrm{O}$ core 
(a)

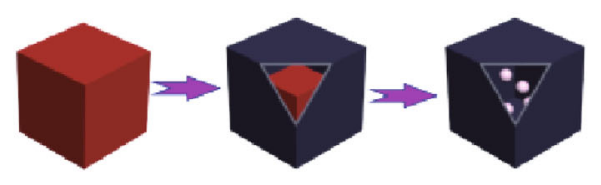

$\mathrm{S}^{2-} \mathrm{H}^{+}$

$\mathrm{Cu}_{2} \mathrm{O} \quad \mathrm{Cu}_{2} \mathrm{O} @ \mathrm{CuSCu} @ \mathrm{CuS}$

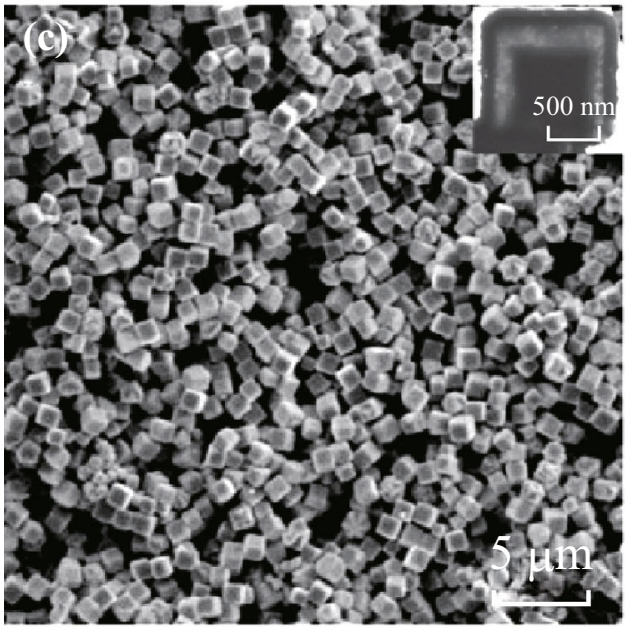

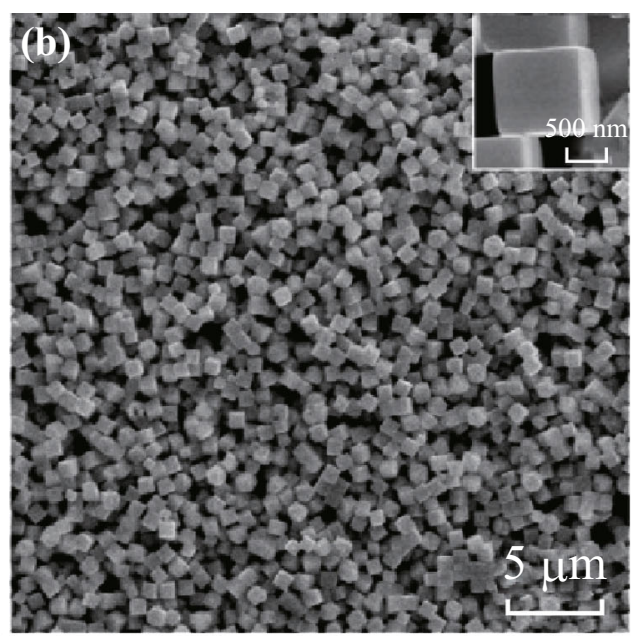

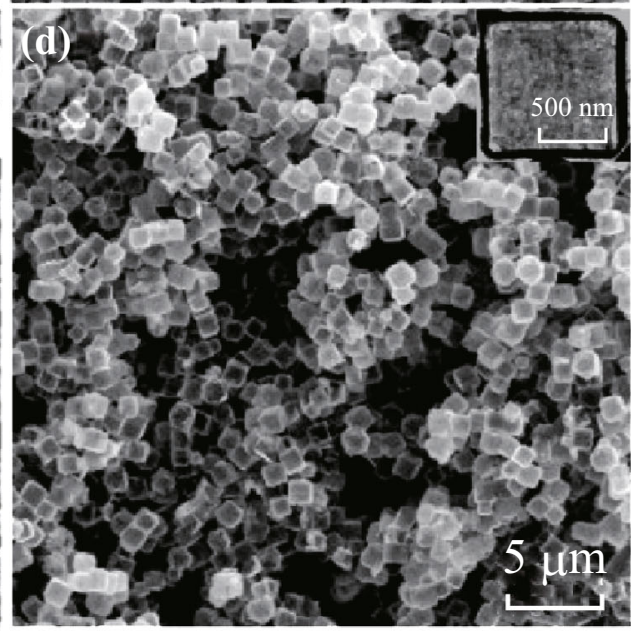

Fig. 1 a Schematic illustration of the formation mechanism of cubic $\mathrm{Cu} @ \mathrm{CuS}$ yolk-shell structures. SEM images of $\mathbf{b} \mathrm{Cu} \mathrm{u}_{2} \mathrm{O}$ solid cubes (the inset shows the corresponding enlarged image), $\mathbf{c} \mathrm{Cu}_{2} \mathrm{O} @ \mathrm{CuS}$ yolk-shell structures, and $\mathbf{d}$ single-shell $\mathrm{Cu} @ \mathrm{CuS}$ yolk-shell structures. The insets in $\mathbf{c}$ and $\mathbf{d}$ show the corresponding TEM images

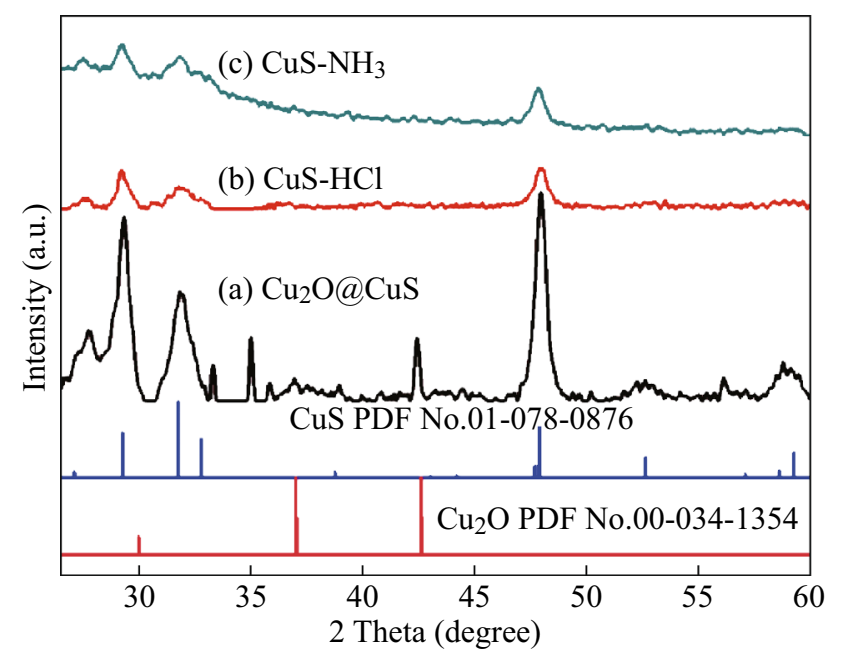

Fig. 2 XRD patterns of a cubic $\mathrm{Cu}_{2} \mathrm{O} @ \mathrm{CuS}$, b products after hydrochloric acid reaction, and $\mathbf{c}$ products after ammonia reaction disappeared and the corresponding hollow cubes could be generated after acidic treatment, suggesting the conversion of $\mathrm{Cu}_{2} \mathrm{O}$ cubes to $\mathrm{Cu}$ crystals. However, no diffraction peaks corresponding to $\mathrm{Cu}$ were found in the XRD pattern (Fig. 2b), most likely due to its low content and poor crystalline. Actually, the $\mathrm{Cu}_{2} \mathrm{O}$ core of the $\mathrm{Cu}_{2} \mathrm{O} @ \mathrm{CuS}$ particles could be completely dissolved by ammonia complexation reaction to form $\left[\mathrm{Cu}\left(\mathrm{NH}_{3}\right)_{4}\right]^{+}$and hollow $\mathrm{CuS}$ boxes. The composition and morphology of the products were examined by XRD (Fig. 2c), SEM, and TEM analyses (Fig. S3).

In order to further confirm the composition and structural information of the $\mathrm{Cu} @ \mathrm{CuS}$ structures, the products were characterized by HRTEM and selected-area electron diffraction (SAED). In agreement with the FESEM findings, a high uniformity of the hollow cubes can be seen in the TEM images (Fig. 3a). Moreover, the inner cavities are clearly revealed by the sharp contrast between shells and 
hollow interiors. The TEM images at higher magnifications depict the inner cavities of the hollow cubes (Fig. 3b). Interestingly, it appears that some small particles with a size of several nanometers are present in the cavities (Fig. 3c). The SAED pattern corresponding to the square shell is displayed in Fig. 3e, and it shows that the square shell has a single crystalline characteristic, and it can be indexed to a primitive hexagonal phase of $\mathrm{CuS}$ viewed along the $[000 \overline{1}]$ zone axis. Moreover, some additional spots correspond well to the (200) reflections of the facecentered cubic $\mathrm{Cu}$. The detailed microstructure of the square shell was further investigated by HRTEM. As shown in Fig. 3d, the corresponding lattice spacing is $0.27 \mathrm{~nm}$, which is in good agreement with the $d$ value of the $(60 \overline{6} 0)$ facets of the hexagonal phase of CuS. The electron diffraction and HRTEM results further confirm that the as-prepared products are comprised of $\mathrm{CuS}$ and $\mathrm{Cu}$.

This shell sulfidation and core disproportionation strategy can also be used to synthesize Cu@CuS yolk-shell structures with different morphologies (octahedral, truncated octahedral, and cuboctahedral). Figure 4 shows the SEM images of the different morphologies of $\mathrm{Cu}_{2} \mathrm{O}$ before and after the sulfidation and disproportionation processes. Firstly, different shapes of the $\mathrm{Cu}_{2} \mathrm{O}$ particles with a smooth surface were synthesized by changing the reaction conditions (Fig. $4 a_{1}-c_{1}$ ). After the sulfidation treatment, the surface of the particles became rough (Fig. $4 \mathrm{a}_{2}-\mathrm{c}_{2}$ ). Selecting the octahedral shape as example XRD analysis (Fig. S4) was carried out to determine the structure and composition of the obtained samples. The diffraction peaks can be ascribed to hexagonal $\mathrm{CuS}$ and cubic $\mathrm{Cu}_{2} \mathrm{O}$, indicating that the as-prepared products are composites of $\mathrm{CuS}$ and $\mathrm{Cu}_{2} \mathrm{O}$ phases. According to the above strategy, $\mathrm{Cu}_{2} \mathrm{O}$ can be used to synthesize spatially confined $\mathrm{Cu}$ particles by a disproportionation reaction. From the SEM images (Fig. $4 \mathrm{a}_{3}-$ $\mathrm{c}_{3}$ ), the products still retain the original morphologies and the interior cavity is formed after the disproportionation reaction. The TEM images (Fig. 5a-c) of $\mathrm{Cu}_{2} \mathrm{O}$ octahedrons depict the inner cavities, and some small $\mathrm{Cu}$ particles appear in the cavities. The color of the solution turned blue-green (Fig. S5), which indicates that the $\mathrm{Cu}_{2} \mathrm{O}$ in the core has disappeared. Therefore, $\mathrm{Cu} @ \mathrm{CuS}$ yolk-shell structures with different morphologies can be synthesized utilizing this disproportionation method (Fig. 4b, c).

The photocatalytic activity of the $\mathrm{Cu} @ \mathrm{CuS}$ cubes was evaluated by MB degradation under sunlight irradiation. As shown in Fig. 6a, when the $\mathrm{Cu} @ \mathrm{CuS}$ cubes were used as photocatalyst, the degradation could be finished within $200 \mathrm{~min}$, and the photographs indicate that the solution became colorless after $200 \mathrm{~min}$ (inset Fig. 6a). The
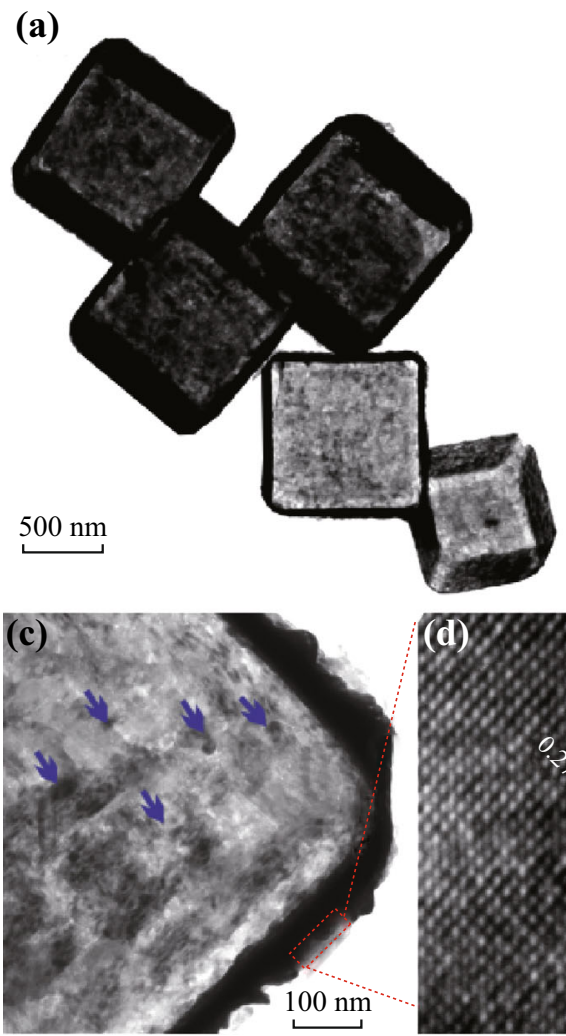
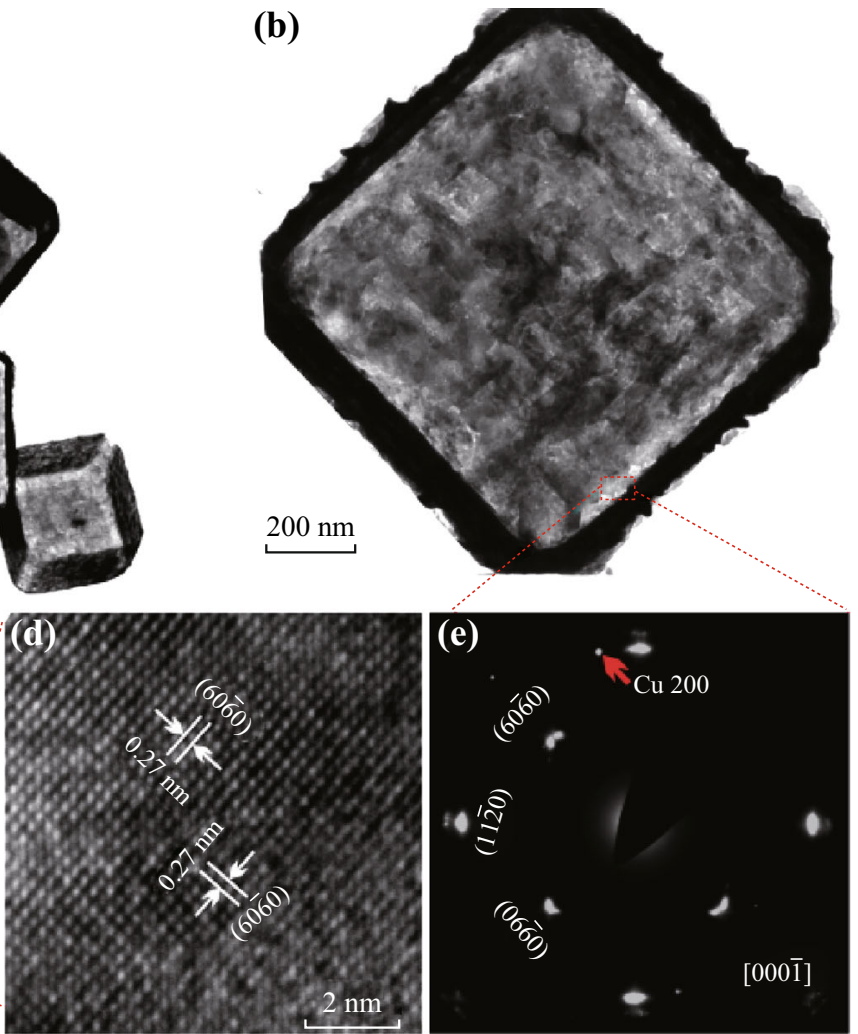

Fig. 3 a Typical TEM image of cubic CuS@Cu yolk-shell structures. b, c Different magnification of the TEM image of individual Cu@CuS yolk-shell structures. d HRTEM image taken from the shell of a $\mathrm{Cu} @ \mathrm{CuS}$ yolk-shell structure. e The corresponding SAED pattern 

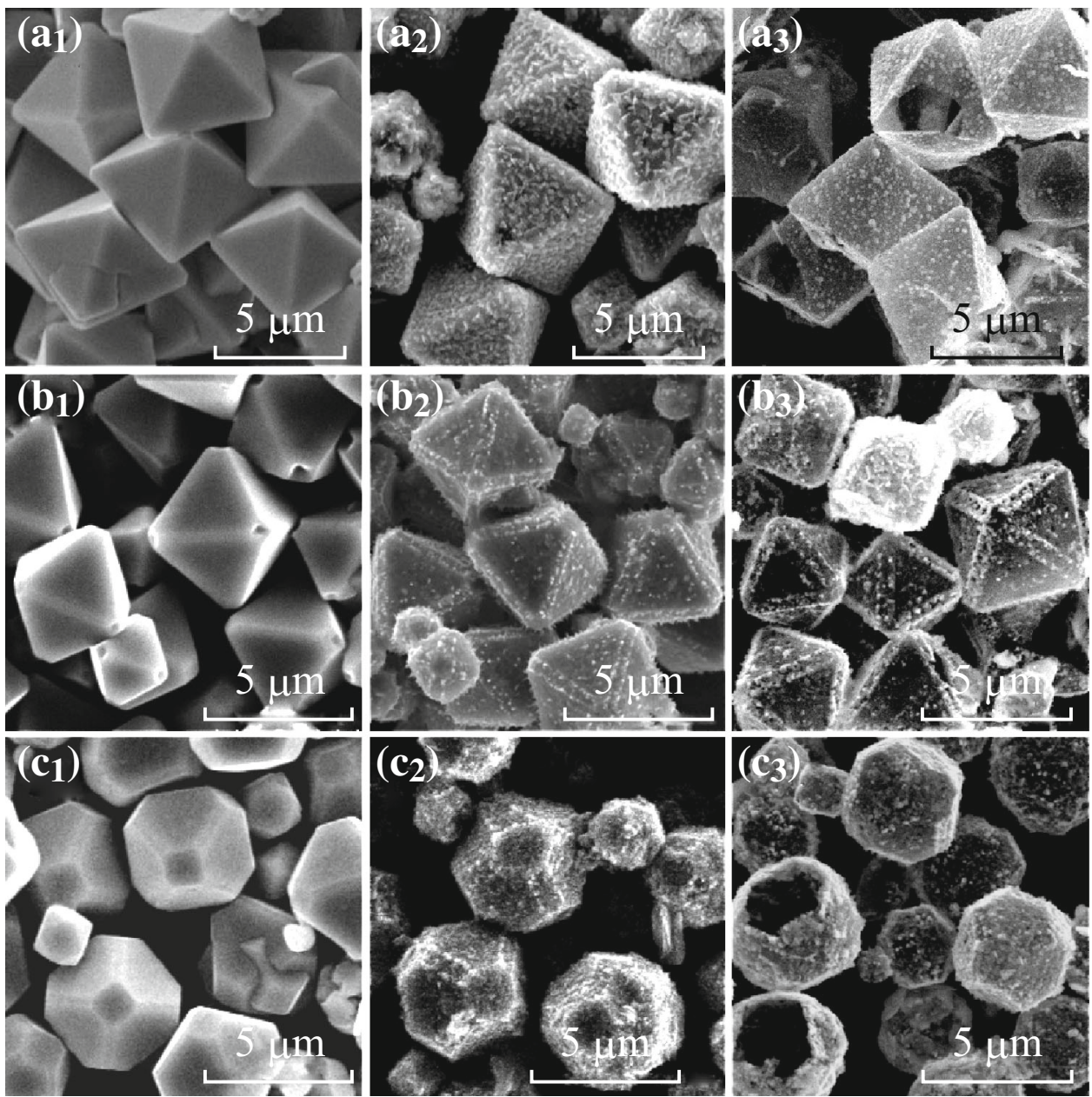

Fig. 4 SEM images of different morphologies of $\mathrm{Cu}_{2} \mathrm{O}$ before and after the sulfidation-disproportionation process: a octahedral shape, b truncated octahedral shape, and $\mathbf{c}$ cuboctahedral shape
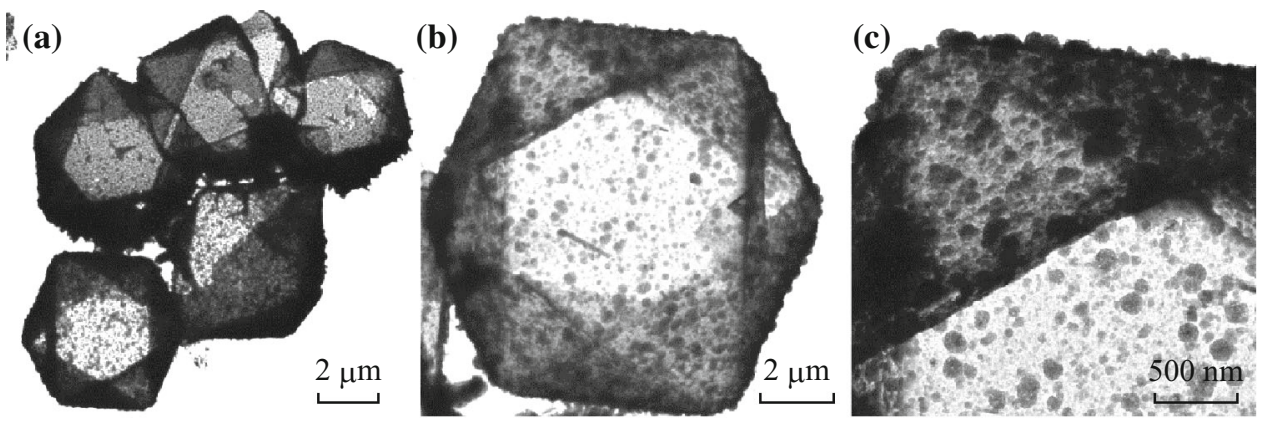

Fig. 5 TEM images of $\mathrm{Cu} @ \mathrm{CuS}$ octahedrons at different magnifications

normalized temporal concentration changes $\left(C_{\mathrm{t}} / C_{0}\right)$ of $\mathrm{MB}$ during the photocatalytic process are proportional to the normalized maximum absorbance $\left(A_{\mathrm{t}} / A_{0}\right)$, which can be derived from the change in the MB absorption profile at a given time interval. Figure $4 \mathrm{~b}$ clearly shows that the photocatalytic activity of the $\mathrm{Cu} @ \mathrm{CuS}$ cubes is higher than that of the CuS cubes. A linear relation of $\ln \left(C_{\mathrm{t}} / C_{0}\right)$ versus reaction time is observed, implying that the photocatalytic reaction can be considered as a pseudo-first-order reaction (Fig. 4c). The cubic $\mathrm{Cu} @ \mathrm{CuS}$ yolk-shell catalysts showed the fastest reaction rate, and the apparent kinetic rate constant was estimated to be $1.18 \times 10^{-2} \mathrm{~min}^{-1}$, which is higher than that of the CuS cubes $\left(3.65 \times 10^{-3} \mathrm{~min}^{-1}\right)$. In order to evaluate the catalytic stability, we carried out the cycle performance of double-shell structure $\mathrm{Cu} @ \mathrm{CuS}$ cubic catalysts for the degradation of MB under solar light 
(a)

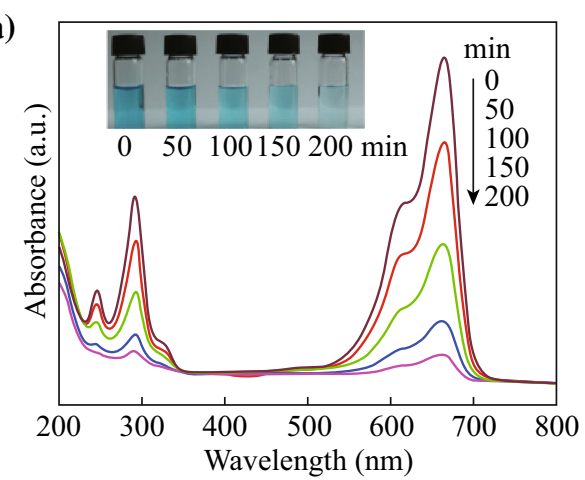

(c)

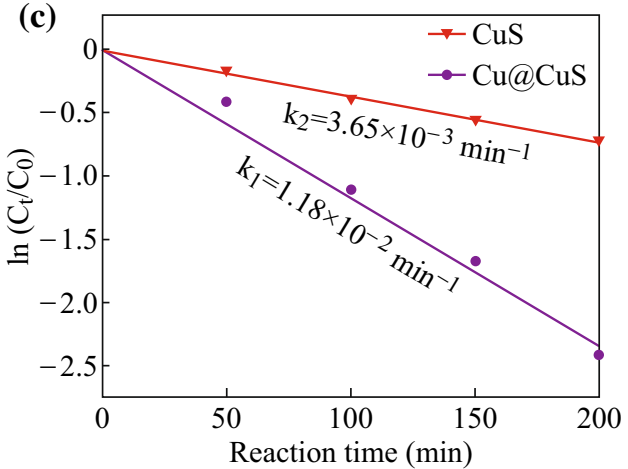

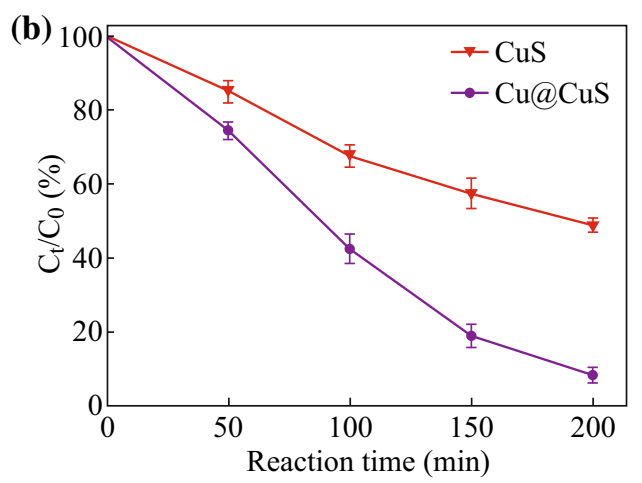

(d)

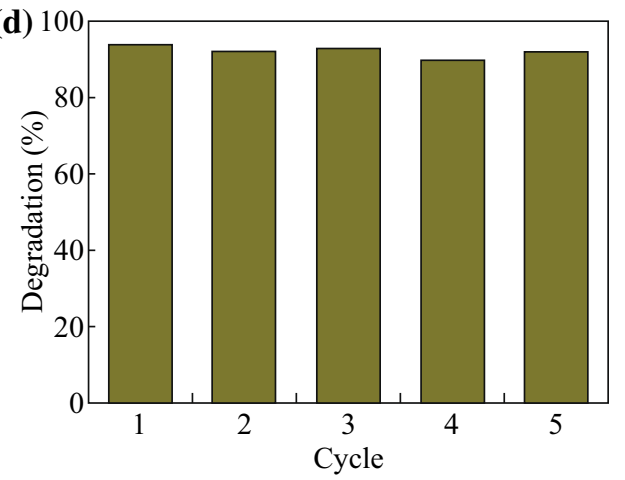

Fig. 6 a UV-Vis absorption spectra of $\mathrm{MB}$ as a function of the xenon lamp (simulated sunlight) irradiation time for $\mathrm{Cu} @ \mathrm{Cu} \mathrm{O}_{2} \mathrm{O}$ cubes. The inset shows the corresponding photographs of $\mathrm{MB}$ irradiated by a xenon lamp for different periods of time. b Photocatalytic degradation curves of MB over different photocatalysts. c Plot of $\ln \left(C_{\mathrm{t}} / C_{0}\right)$ as a function of time over different catalysts. d Cycle stability of Cu@Cu $\mathrm{C}_{2} \mathrm{O}$ cubes

irradiation (Fig. 4d). The results reveal that the $\mathrm{Cu} @ \mathrm{CuS}$ cubic structures possess an outstanding catalytic stability, which remains above $90 \%$ in the photodegradation of MB after five cycle tests.

The enhanced photocatalytic activity of $\mathrm{Cu} @ \mathrm{CuS}$ cubes might be mainly ascribed to a reduced electron-hole pair recombination owing to the $\mathrm{Cu} / \mathrm{CuS}$ hybrid nanostructures, as confirmed by EIS measurements (Fig. 7). The low charge-transfer resistance $\left(R_{\mathrm{ct}}\right)$ indicates that the coupled system of semiconductors decreases the layer resistance in the solid-state interface and the charge-transfer resistance on the surface. Therefore, the above results indicate that the present copper can act as an electron sink to effectively transfer the photogenerated electrons of the photocatalyst $\left(\mathrm{Cu}_{2} \mathrm{~S}\right)$, which may slow down the recombination of photogenerated electrons and holes to provide a high photocatalytic activity $[35,36]$.

\section{Conclusions}

In summary, we have developed a new and efficient shell sulfidation and core disproportionation strategy for the synthesis of non-spherical Cu@CuS yolk-shell structures. This method can be used to fabricate Cu@CuS yolk-shell

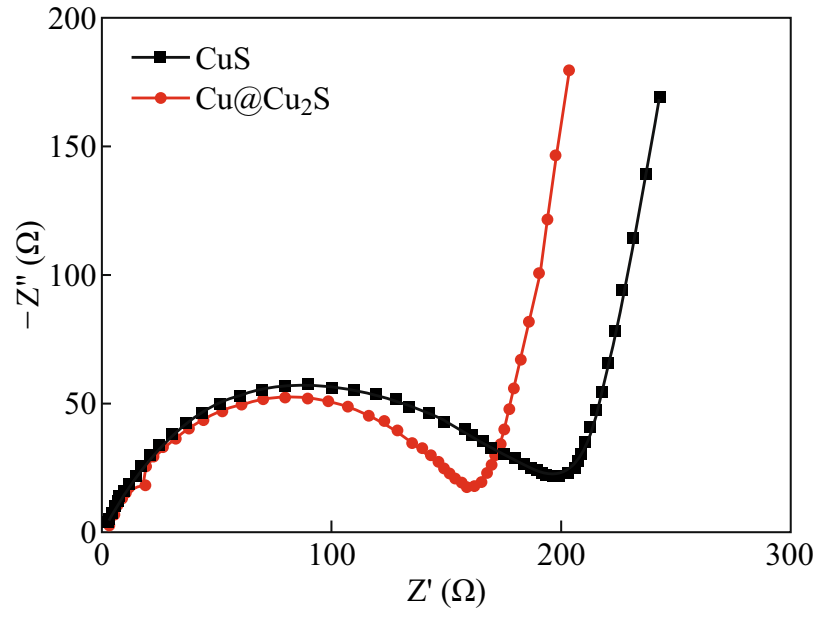

Fig. 7 Nyquist plots of $\mathrm{CuS}$ and $\mathrm{Cu} @ \mathrm{CuS}$ cube samples

structures with different morphologies (cubic, octahedral, and cuboctahedral). The void space in the hollow structures provides a unique confined space, where a metal copper present in the core of a shell can be protected from agglomeration and oxidation. Furthermore, due to the presence of metal copper and hollow structures, the $\mathrm{Cu} @ \mathrm{CuS}$ yolk-shell structures manifest excellent photocatalytic activity and stability under sunlight irradiation. 
Acknowledgements This work was supported by the National Natural Science Foundation of China (Grant Nos. 21671085, 21473081, 21201088), the Natural Science Foundation of Jiangsu Province (BK20161160), the Qing Lan Project and the Project Funded by the Priority Academic Program Development of Jiangsu Higher Education Institutions.

Open Access This article is distributed under the terms of the Creative Commons Attribution 4.0 International License (http://crea tivecommons.org/licenses/by/4.0/), which permits unrestricted use, distribution, and reproduction in any medium, provided you give appropriate credit to the original author(s) and the source, provide a link to the Creative Commons license, and indicate if changes were made.

\section{References}

1. A. Fujishima, K. Honda, Three-dimensional structure of thermolysin. Nature 238, 37-41 (1972). doi:10.1038/ newbio238037a0

2. X.B. Chen, S.H. Shen, L.J. Guo, S.S. Mao, Semiconductor-based photocatalytic hydrogen generation. Chem. Rev. 110, 6503-6570 (2010). doi:10.1021/cr1001645

3. Z.G. Yi, J.H. Ye, N. Kikugawa, T. Kako, S.X. Ouyang et al., An orthophosphate semiconductor with photooxidation properties under visible-light irradiation. Nat. Mater. 9, 559-564 (2010). doi: $10.1038 /$ nmat 2780

4. P. Zhang, L. Wang, X. Zhang, C. Shao, J. Hu, G. Shao, Threedimensional porous networks of ultra-long electrospun $\mathrm{SnO}_{2}$ nanotubes with high photocatalytic performance. Nano-Micro Lett. 7(1), 86-95 (2015). doi:10.1007/s40820-014-0022-4

5. J.S. Hu, L.L. Ren, Y.G. Guo, H.P. Liang, A.M. Cao, L.J. Wan, C.L. Bai, Mass production and high photocatalytic activity of $\mathrm{ZnS}$ nanoporous nanoparticles. Angew. Chem. Int. Ed. 117, 1295-1299 (2005). doi:10.1002/ange.200462057

6. H.F. Cheng, B.B. Huang, X.Y. Qin, X.Y. Zhang, Y. Dai, A controlled anion exchange strategy to synthesize $\mathrm{Bi}_{2} \mathrm{~S}_{3}$ nanocrystals/BiOCl hybrid architectures with efficient visible light photoactivity. Chem. Commun. 48, 97-99 (2012). doi:10. 1039/C1CC15487G

7. Q.W. Tian, J.Q. Hu, Y.H. Zhu, R.J. Zou, Z.G. Chen et al., Sub$10 \mathrm{~nm} \mathrm{Fe}_{3} \mathrm{O}_{4} @ \mathrm{Cu}_{2-x} \mathrm{~S}$ core-shell nanoparticles for dual-modal imaging and photothermal therapy. J. Am. Chem. Soc. 135(23), 8571-8577 (2013). doi:10.1021/ja4013497

8. J.F. Mao, Q. Shu, Y.Q. Wen, H.Y. Yuan, D. Xiao, M.F. Choi, Facile fabrication of porous cus nanotubes using well-aligned $[\mathrm{Cu}(\mathrm{tu})] \mathrm{Cl}_{1 / 2} \mathrm{H}_{2} \mathrm{O}$ nanowire precursors as self-sacrificial templates. Cryst. Growth Des. 9(6), 2546-2548 (2009). doi:10.1021/ $\operatorname{cg} 8006052$

9. F. Pan, S.M. Niu, Y. Ding, L. Dong, R.M. Yu, Y. Liu, G. Zhu, Z.L. Wang, Enhanced $\mathrm{Cu}_{2} \mathrm{~S} / \mathrm{CdS}$ coaxial nanowire solar cells by piezo-phototronic effect. Nano Lett. 12(6), 3302-3307 (2012). doi: $10.1021 / \mathrm{nl} 3014082$

10. Z.J. Sun, X. Liu, Q.D. Yue, H.X. Jia, P.W. Du, Cadmium sulfide nanorods decorated with copper sulfide via one-step cation exchange approach for enhanced photocatalytic hydrogen evolution under visible light. Chemcatchem 8, 157-162 (2016). doi: $10.1002 /$ cctc. 201500789

11. H.B. Wu, W. Chen, Synthesis and reaction temperature-tailored self-assembly of copper sulfide nanoplates. Nanoscale 3, 5096-5102 (2011). doi:10.1039/c1nr10829h

12. Z.G. Chen, S.Z. Wang, Q. Wang, B.Y. Geng, A facile solution chemical route to self-assembly of $\mathrm{CuS}$ ball-flowers and their application as an efficient photocatalyst. CrystEngComm 12, 144-149 (2010). doi:10.1039/B914902C

13. H. Kuo, Y.T. Chu, Y.F. Song, M.H. Huang, $\mathrm{Cu}_{2} \mathrm{O}$ nanocrystaltemplated growth of $\mathrm{Cu}_{2} \mathrm{~S}$ nanocages with encapsulated au nanoparticles and in situ transmission X-ray microscopy study. Adv. Funct. Mater. 21, 792-797 (2011). doi:10.1002/adfm. 201002108

14. J. Reszczynska, T. Grzyb, J.W. Sobczak, W. Lisowski, M. Gazda, B. Ohtani, A. Zaleska, Visible light activity of rare earth metal doped $\left(\mathrm{Er}^{3+}, \mathrm{Yb}^{3+}\right.$ or $\left.\mathrm{Er}^{3+} / \mathrm{Yb}^{3+}\right)$ titania photocatalysts. Appl. Catal. B-Environ. 163, 40-49 (2015). doi:10.1016/j.apcatb.2014. 07.010

15. J.Z. Bloh, R. Dillert, D.W. Bahnemann, Designing optimal metaldoped photocatalysts: correlation between photocatalytic activity, doping ratio, and particle size. J. Phys. Chem. C 116(48), 25558-25562 (2012). doi:10.1021/jp307313z

16. J.Y. Qin, J.P. Huo, P.Y. Zhang, J. Zeng, T.T. Wang, H.P. Zeng, Improving the photocatalytic hydrogen production of $\mathrm{Ag} / \mathrm{g}-\mathrm{C}_{3} \mathrm{~N}_{4}$ nanocomposites by dye-sensitization under visible light irradiation. Nanoscale 8, 2249-2259 (2016). doi:10.1039/C5NR06346A

17. K. Kim, M.J. Kim, S. Kim, J.H. Jang, Towards visible light hydrogen generation: quantum dot-sensitization via efficient light harvesting of hybrid- $\mathrm{TiO}_{2}$. Sci. Rep. 3, 3330 (2013). doi:10.1038/ srep03330

18. S.S. Chen, Y. Qi, T. Hisatomi, Q. Ding, T. Asai et al., Efficient visible-light-driven $\mathrm{z}$-scheme overall water splitting using a MgTa2O6-xNy/TaON heterostructure photocatalyst for $\mathrm{H} 2$ evolution. Angew. Chem. Int. Ed. 127, 8618-8621 (2015). doi:10. 1002/ange. 201502686

19. J. Jiang, H. Li, L.Z. Zhang, New insight into daylight photocatalysis of AgBr@Ag: synergistic effect between semiconductor photocatalysis and plasmonic photocatalysis. Chem. Eur. J. 18, 6360-6369 (2012). doi:10.1002/chem.201102606

20. W. Ding, K. Liu, S.N. He, C.B. Gao, Y.D. Yin, Ligand-exchange assisted formation of $\mathrm{Au} / \mathrm{TiO}_{2}$ schottky contact for visible-light photocatalysis. Nano Lett. 14(11), 6731-6736 (2014). doi:10. $1021 / \mathrm{n} 1503585 \mathrm{~m}$

21. S.N. Xiao, P.J. Liu, W. Zhu, G.S. Li, D.Q. Zhang, H.X. Li, Copper nanowires: a substitute for noble metals to enhance photocatalytic $\mathrm{H}_{2}$ generation. Nano Lett. 15(8), 4853-4858 (2015). doi:10.1021/acs.nanolett.5b00082

22. Y. Li, W.N. Wang, Z.L. Zhan, M.H. Woo, C.Y. Wu, P. Biswas, Photocatalytic reduction of $\mathrm{CO}_{2}$ with $\mathrm{H}_{2} \mathrm{O}$ on mesoporous silica supported $\mathrm{Cu} / \mathrm{TiO}_{2}$ catalysts. Appl. Catal. B-Environ. 100, 386-392 (2010). doi:10.1016/j.apcatb.2010.08.015

23. X. Lai, J.E. Halpert, D. Wang, Recent advances in micro-/nanostructured hollow spheres for energy applications: from simple to complex systems. Energy Environ. Sci. 5, 5604-5618 (2012). doi:10.1039/C1EE02426D

24. N. Liu, H. Wu, M.T. McDowell, Y. Yao, C.M. Wang, Y. Cui, A yolk-shell design for stabilized and scalable li-ion battery alloy anodes. Nano Lett. 12(6), 3315-3321 (2012). doi:10.1021/ nl3014814

25. H. Hu, B.Y. Guan, B.Y. Xia, X.W. Lou, Sub-10 nm $\mathrm{Fe}_{3} \mathrm{O}_{4} @$ $\mathrm{Cu}_{2-x} \mathrm{~S}$ core-shell nanoparticles for dual-modal imaging and photothermal therapy. J. Am. Chem. Soc. 135(23), 8571-8577 (2013). doi:10.1021/ja4013497

26. L.L. Wang, H.M. Dou, Z. Lou, T. Zhang, Encapsuled nanoreactors $\left(\mathrm{Au} @ \mathrm{SnO}_{2}\right)$ : a new sensing material for chemical sensors. Nanoscale 5, 2686-2691 (2013). doi:10.1039/c2nr33088a

27. L.L. Wang, Z. Lou, J.N. Deng, R. Zhang, T. Zhang, Ethanol gas detection using a yolk-shell (core-shell) $\alpha-\mathrm{Fe}_{2} \mathrm{O}_{3}$ nanospheres as sensing material. ACS Appl. Mater. Interfaces 7, 13098-13104 (2015). doi:10.1021/acsami.5b03978

28. L.L. Wang, W.B. Ng, J.A. Jackman, N.J. Cho, Graphene-functionalized natural microcapsules: modular building blocks for 
ultrahigh sensitivity bioelectronic platforms. Adv. Funct. Mater. 26, 2097-2103 (2016). doi:10.1002/adfm.201504940

29. Y.R. Wang, W.L. Yang, L. Zhang, Y. Hu, X.W. Lou, Formation of MS-Ag and MS (M = Pb, Cd, $\mathrm{Zn})$ nanotubes via microwaveassisted cation exchange and their enhanced photocatalytic activities. Nanoscale 5, 10864-10867 (2013). doi:10.1039/ c3nr03909a

30. S.H. Ye, X.J. He, L.X. Ding, Z.W. Pan, Y.X. Tong, M.M. Wu, G.R. $\mathrm{Li}, \mathrm{Cu}_{2} \mathrm{O}$ template synthesis of high-performance $\mathrm{PtCu}$ alloy yolk-shell cube catalysts for direct methanol fuel cells. Chem. Commun. 50, 12337-12340 (2014). doi:10.1039/C4CC04108A

31. L. Kuai, B.Y. Geng, S.Z. Wang, Y. Sang, A general and highyield galvanic displacement approach to $\mathrm{AuM}(\mathrm{M}=\mathrm{Au}, \mathrm{Pd}$, and $\mathrm{Pt}$ ) core-shell nanostructures with porous shells and enhanced electrocatalytic performances. Chem. Eur. J. 18, 9423-9429 (2012). doi:10.1002/chem.201200893

32. Y. Lu, Y. Zhao, L. Yu, L. Dong, C. Shi, M.J. Hu, Y.J. Xu, L.P. Wen, S.H. Yu, Hydrophilic Co@Au yolk/shell nanospheres: synthesis, assembly, and application to gene delivery. Adv. Mater. 22, 1407-1411 (2010). doi:10.1002/adma.200903298
33. Z.H. Wei, Z.J. Zhou, M. Yang, C.H. Lin, Z.H. Zhao, D.T. Huang, Z. Chen, J.H. Cao, Multifunctional $\mathrm{Ag} @ \mathrm{Fe}_{2} \mathrm{O}_{3}$ yolk-shell nanoparticles for simultaneous capture, kill, and removal of pathogen. J. Mater. Chem. 21, 16344-16348 (2011). doi:10.1039/ c1jm13691g

34. S.D. Sun, X.P. Song, C.C. Kong, S.H. Liang, B.J. Ding, Z.M. Yang, Unique polyhedral 26-facet $\mathrm{CuS}$ hollow architectures decorated with nanotwinned, mesostructural and single crystalline shells. CrystEngComm 13, 6200-6205 (2011). doi:10. 1039/c1ce05563a

35. Q.P. Luo, X.Y. Yu, B.X. Lei, H.Y. Chen, D.B. Kuang, C.Y. Su, Reduced graphene oxide-hierarchical zno hollow sphere composites with enhanced photocurrent and photocatalytic activity. J. Phys. Chem. C 116(14), 8111-8117 (2012). doi:10.1021/jp2113329

36. X.W. Zou, H.Q. Fan, Y.M. Tian, M.G. Zhang, X.Y. Yan, Microwave-assisted hydrothermal synthesis of $\mathrm{Cu} / \mathrm{Cu}_{2} \mathrm{O}$ hollow spheres with enhanced photocatalytic and gas sensing activities at room temperature. Dalton Trans. 44, 7811-7821 (2015). doi:10. 1039/C4DT03417A 